\title{
Front Matter: Volume 10617
}

, "Front Matter: Volume 10617," Proc. SPIE 10617, 2017 International Conference on Optical Instruments and Technology: Optoelectronic Devices and Optical Signal Processing, 1061701 (12 January 2018); doi: 10.1117/12.2316707

SPIE Event: International Conference on Optical Instruments and Technology 2017, 2017, Beijing, China 


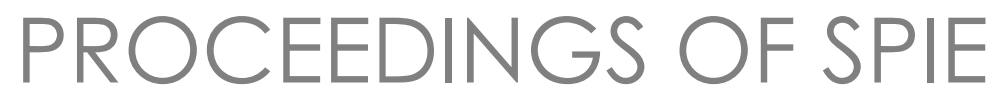

\title{
2017 International Conference on Optical Instruments and Technology \\ Optoelectronic Devices and Optical Signal Processing
}

\author{
Yi Dong \\ Jian Chen \\ Fabien Bretenaker \\ Editors
}

28-30 October 2017

Beijing, China

Sponsored by

CIS - China Instrument and Control Society (China)

SPIE

Published by

SPIE 
The papers in this volume were part of the technical conference cited on the cover and title page. Papers were selected and subject to review by the editors and conference program committee. Some conference presentations may not be available for publication. Additional papers and presentation recordings may be available online in the SPIE Digital Library at SPIEDigitalLibrary.org.

The papers reflect the work and thoughts of the authors and are published herein as submitted. The publisher is not responsible for the validity of the information or for any outcomes resulting from reliance thereon.

Please use the following format to cite material from these proceedings:

Author(s), "Title of Paper," in 2017 International Conference on Optical Instruments and Technology: Optoelectronic Devices and Optical Signal Processing, edited by Yi Dong, Jian Chen, Fabien Bretenaker, Proceedings of SPIE Vol. 10617 (SPIE, Bellingham, WA, 2018) Seven-digit Article CID Number.

ISSN: 0277-786X

ISSN: 1996-756X (electronic)

ISBN: 9781510617452

ISBN: 9781510617469 (electronic)

Published by

SPIE

P.O. Box 10, Bellingham, Washington 98227-0010 USA

Telephone +1 3606763290 (Pacific Time) · Fax +1 3606471445

SPIE.org

Copyright (C) 2018, Society of Photo-Optical Instrumentation Engineers.

Copying of material in this book for internal or personal use, or for the internal or personal use of specific clients, beyond the fair use provisions granted by the U.S. Copyright Law is authorized by SPIE subject to payment of copying fees. The Transactional Reporting Service base fee for this volume is $\$ 18.00$ per article (or portion thereof), which should be paid directly to the Copyright Clearance Center (CCC), 222 Rosewood Drive, Danvers, MA 01923. Payment may also be made electronically through CCC Online at copyright.com. Other copying for republication, resale, advertising or promotion, or any form of systematic or multiple reproduction of any material in this book is prohibited except with permission in writing from the publisher. The CCC fee code is 0277$786 \mathrm{X} / 18 / \$ 18.00$.

Printed in the United States of America.

Publication of record for individual papers is online in the SPIE Digital Library.

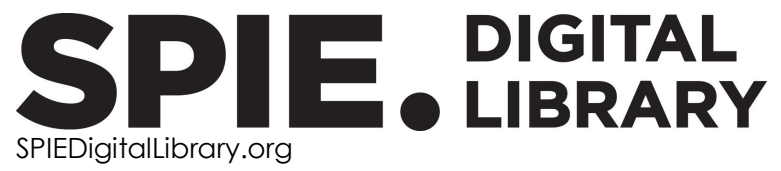

Paper Numbering: Proceedings of SPIE follow an e-First publication model. A unique citation identifier (CID) number is assigned to each article at the time of publication. Utilization of CIDs allows articles to be fully citable as soon as they are published online, and connects the same identifier to all online and print versions of the publication. SPIE uses a seven-digit CID article numbering system structured as follows:

- The first five digits correspond to the SPIE volume number.

- The last two digits indicate publication order within the volume using a Base 36 numbering system employing both numerals and letters. These two-number sets start with $00,01,02,03$, 04, 05, 06, 07, 08, 09, OA, OB ... 0Z, followed by 10-1Z, 20-2Z, etc. The CID Number appears on each page of the manuscript. 


\title{
Contents
}

\author{
vii Authors \\ ix Symposium Committee \\ xi Conference Committee \\ xiii Introduction \\ xv Conference Organizers
}

\section{SESSION 1}

1061702 Study on the characteristic and application of DFB semiconductor lasers under optical injection for microwave photonics (Invited Paper) [10617-50]

1061703 Experimental demonstration of optical XOR and XNOR based on polarization interference [10617-4]

1061704 Efficient dynamic coherence transfer relying on offset locking using optical phase-locked loop [10617-17]

\section{SESSION 2}

1061705 DFB laser array driver circuit controlled by adjustable signal [10617-34]

1061706 Study of the thermal-induced intensity balanced Nd:GdVO 4 microchip dual-frequency laser [10617-48]

\section{SESSION 3}

1061707 High-speed optical transmission system using $\mathbf{1 . 5 5}$ - $\mu \mathrm{m}$ directly modulated lasers (Invited Paper) [10617-23]

1061708 A novel method for chromatic dispersion estimation with lower computation complexity in fractional domain [10617-11]

1061709 The wavefront compensation of free space optics utilizing micro corner-cube-reflector arrays [10617-29] 
10617 OA MIMO signal progressing with RLSCMA algorithm for multi-mode multi-core optical transmission system (Invited Paper) [10617-42]

10617 OB Chaos-based CAZAC scheme for secure transmission in OFDM-PON [10617-26]

10617 OC Circle-16QAM for a zero-guard-interval CO-OFDM system [10617-46]

10617 OD The effect of jitter on the performance of space coherent optical communication system with Costas loop [10617-7]

\section{SESSION 5}

10617 OE Energy-aware virtual network embedding in flexi-grid optical networks (Invited Paper) [10617-27]

10617 OF Investigation of homodyne demodulation of RZ-BPSK signal based on an optical Costas loop [10617-47]

10617 OG A highly precise fiber delay fluctuation measurement with a wide range [10617-41]

POSTER SESSION

$10617 \mathrm{OH}$ Propagation of partially coherent vector anomalous vortex beam in turbulent atmosphere [10617-5]

10617 ol Research on detecting spot selection and signal pretreatment of four-quadrant detector [10617-6]

10617 0J Beam-width spreading of vortex beams in free space [10617-12]

10617 OK Effectiveness evaluation of double-layered satellite network with laser and microwave hybrid links based on fuzzy analytic hierarchy process [10617-14]

10617 OL The image acquisition system design of floor grinder [10617-22]

10617 OM An optical tunable filter array based on LCOS phase grating [10617-28]

10617 ON Two-dimensional priority-based dynamic resource allocation algorithm for QoS in WDM/TDM PON networks [10617-32]

10617001 1Mbps NLOS solar-blind Ultraviolet communication system based on UV-LED array [10617-37]

10617 OP A transmitting antenna with hexagon illumination shape for four-color VLC [10617-38]

$106170 Q$ Study on a low complexity adaptive modulation algorithm in OFDM-ROF system with subcarrier grouping technology [10617-40] 
10617 OR Analysis on the propagation characteristics of two multiplexed groups of coaxial OAM beams in atmospheric turbulence [10617-43]

10617 OS An improved adaptive interpolation clock recovery loop based on phase splitting algorithm for coherent optical communication system [10617-44]

10617 OT The application demand analysis of advanced photoelectric technology in the future unmanned vehicle loads [10617-52]

10617 OU Weighted finite impulse response filter for chromatic dispersion equalization in coherent optical fiber communication systems [10617-53]

10617 OV Effective reduction of the phase error for gamma nonlinearity in phase measuring profilometry by BLPF [10617-54]

10617 OW Characteristics of white LED transmission through a smoke screen [10617-56] 
Proc. of SPIE Vol. 10617 1061701-6

Downloaded From: https://www.spiedigitallibrary.org/conference-proceedings-of-spie on 25 Apr 2023 Terms of Use: https://www.spiedigitallibrary.org/terms-of-use 


\section{Authors}

Numbers in the index correspond to the last two digits of the seven-digit citation identifier (CID) article numbering system used in Proceedings of SPIE. The first five digits reflect the volume number. Base 36 numbering is employed for the last two digits and indicates the order of articles within the volume. Numbers start with 00, 01, 02, 03, 04, 05, 06, 07, 08, 09, OA, OB...0Z, followed by 10-12, 20-2Z, etc.

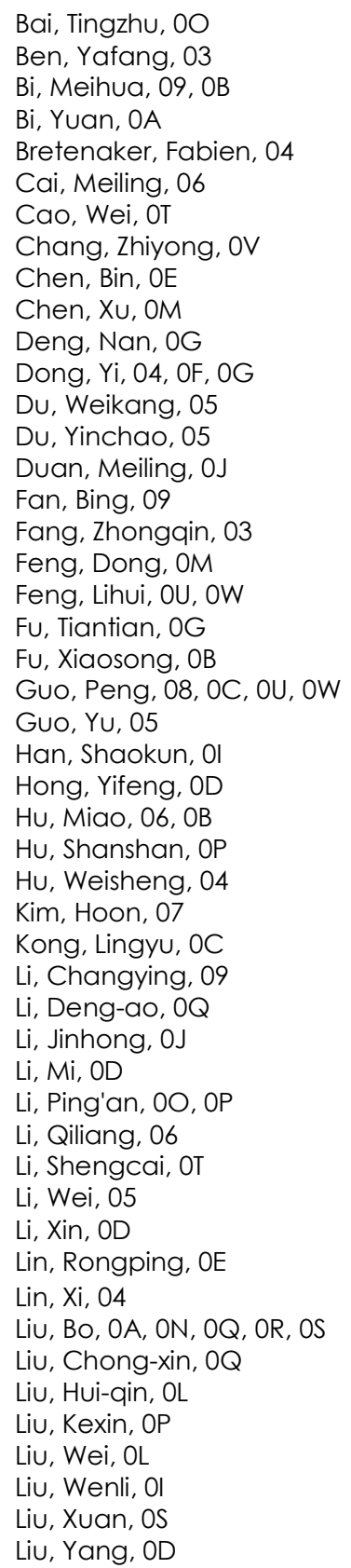

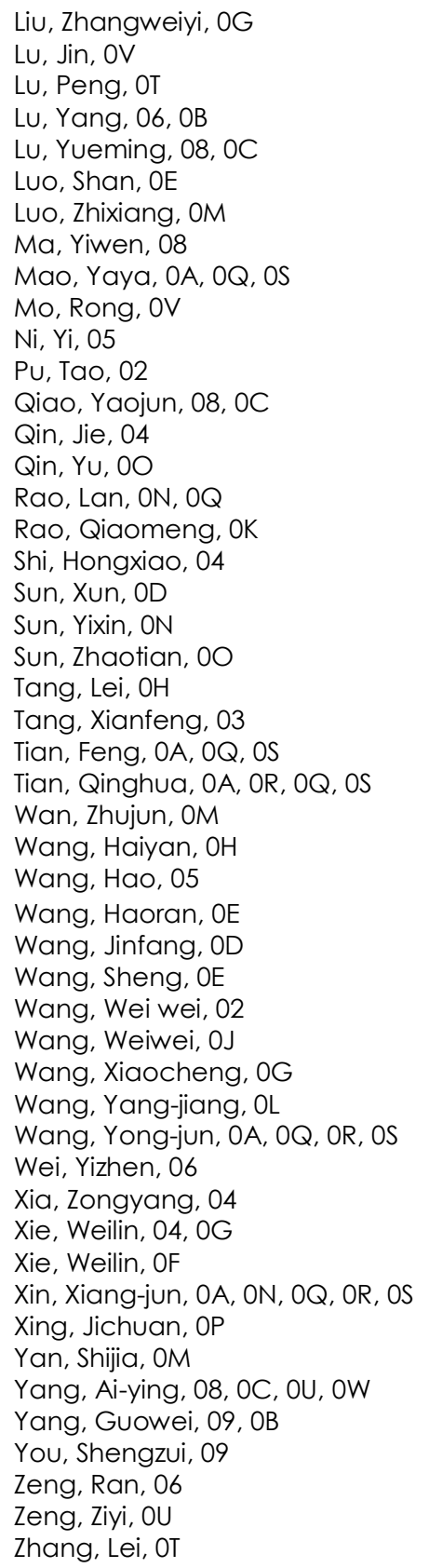


Zhang, Li-jia, OA, ON, OQ, OS

Zhang, Lijun, OO, OP

Zhang, Lin, 04

Zhang, Qi, OA, ON, OR, OS

Zhang, Wei, OK, OR

Zhang, $\mathrm{Xu}, \mathrm{OH}$

Zhao, Xiaxia, OV

Zheng, Yongping, OR

Zheng, Yunfei, OW

Zhou, Haijun, OF

Zhou, Qian, 04

Zhou, Xuefang, 06, OB

Zhu, Lei, OR

Zhu, Zunzhen, OF 


\title{
Symposium Committee
}

\author{
General Chairs \\ Tianchu Li, National Institute of Metrology (China) \\ H. Phillip Stahl, NASA Marshall Space Flight Center (United States) \\ Conference Co-Chairs \\ Songlin Zhuang, Shanghai University of Science and Technology (China) \\ Liwei Zhou, Beijing Institute of Technology (China) \\ Shenghua Ye, Tianjin University (China) \\ Yimo Zhang, Tianjin University (China) \\ Zheng You, Tsinghua University (China) \\ Guangjun Zhang, Southeast University (China)
}

Technical Program Chair

Guofan Jin, Tsinghua University (China)

Technical Program Co-Chairs

Jinxue Wang, SPIE

Tiegen Liu, Tianjin University (China)

Local Organizing Committee Chair

Youhua Wu, China Instrument and Control Society (China)

Local Organizing Committee Co-Chairs

Guoqiang Ni, Beijing Institute of Technology (China)

Daoyin Yu, Tianjin University (China)

General Secretary

Tong Zhang, China Instrument and Control Society (China)

Administrative Vice General Secretary

Yu-nan Sun, Beijing Institute of Technology (China)

Vice General Secretaries

Qun Hao, Beijing Institute of Technology (China)

Yuejin Zhao, Beijing Institute of Technology (China)

Cunlin Zhang, Capital Normal University (China)

Liquan Dong, Beijing Institute of Technology (China) 
Local Organizing Committee

Hongda Chen, Institute of Semiconductors, Chinese Academy of Sciences (China)

Xuping Zhang, Nanjing University (China)

Shangzhong Jin, China Jiliang University (China)

Libo Yuan, Harbin Engineering University (China)

Yumei Wen, Chongqing University (China)

Tian Lan, Beijing Institute of Technology (China)

Cuiling Li, Beijing Institute of Technology (China) 


\title{
Conference Committee
}

\author{
Conference Chairs
}

Yi Dong, Shanghai Jiao Tong University (China)

Jian Chen, Nanjing University of Posts and Telecommunications

(China)

Fabien Bretenaker, Laboratoire Aimé Cotton (France)

Program Committee

Wenshan Cai, Georgia Institute of Technology (United States)

Lu Chao, Hong Kong Polytechnic University (Hong Kong, China)

Zabih Ghassemlooy, Northumbria University (United Kingdom)

Hoon Kim, Korea Advanced Institute of Science and Technology

(Korea, Republic of)

Zhaohui Li, Sun Yat-sen University (China)

Wen-Di Li, The University of Hong Kong (Hong Kong, China)

JianGuo Liu, Institute of Semiconductors, Chinese Academy of Sciences (China)

Hai Ming, University of Science and Technology of China (China)

Tao Pu, PLA University of Science and Technology (China)

Ming Tang, Huazhong University of Science and Technology (China)

Chao Wang, University of Kent (United Kingdom)

Yixin Wang, Institute for Infocomm Research (Singapore)

Yuncai Wang, Taiyuan University of Technology (China)

Kenneth K. Y. Wong, The University of Hong Kong (Hong Kong, China)

Chongqing Wu, Beijing Jiaotong University (China)

Jian Wu, Beijing University of Posts and Telecommunications (China)

Li Xia, Huazhong University of Science and Technology (China)

Xiaoke Yi, University of Sydney (Australia)

Changyuan Yu, The Hong Kong Polytechnic University

(Hong Kong, China)

Jinlong Yu, Tianjin University (China)

Song Yu, Beijing University of Posts and Telecommunications (China)

Shaoliang Zhang, NEC America (United States)

Xiaoping Zheng, Tsinghua University (China)

Zheng Zheng, Beihang University (China)

Wende Zhong, Nanyang Technological University (Singapore)

Weilin Xie (Secretary), Shanghai Jiao Tong University (China) 


\section{Session Chairs}

1 Optical Signal Processing

Jian Chen, Nanjing University of Posts and Telecommunications (China)

2 Optoelectronics Devices

Xiaoke Yi, University of Sydney (Australia)

3 Optical Communication

Jian Wang, Huazhong University of Science and Technology (China)

4 Optical Communication

Changyuan Yu, The Hong Kong Polytechnic University (Hong Kong, China)

5 Optical Communication

Weilin Xie, Shanghai Jiao Tong University (China) 


\section{Introduction}

The advent and progress of novel optoelectronics devices and components, including nano-photonics devices and integrated optics, allow for the achievement of novel optical signal processing systems and subsystems. This would lead to the realization of advanced optical communication systems and networks, optical measurement technologies, and other novel applications. The development of these techniques will facilitate and expedite the implementation of optical systems in all aspects and represent an impressive feat of science and technology in these fields.

The topics of the Optoelectronics Devices and Optical Signal Processing section of OIT'2017 cover integrated photonics, novel optoelectronic devices and technologies, emerging optoelectronic systems and subsystems, and their applications in optical signal processing, optical measurement, sensing, and optical communication systems and networks. More than 40 papers were accepted in this section, which have reported the state-of-the-art progresses, results, and achievements in the relevant communities. 
Proc. of SPIE Vol. 10617 1061701-14 Downloaded From: https://www.spiedigitallibrary.org/conference-proceedings-of-spie on 25 Apr 2023
Terms of Use: https://www.spiedigitallibrary.org/terms-of-use 


\title{
Conference Organizers
}

\author{
Organized by \\ Opto-Electronic-Mechanic Technology and System Integration Chapter, CIS \\ (China) \\ Committee on Optoelectronic Technology, COS (China) \\ Committee on Optics, China Ordnance Society (China) \\ Optical Instrument Chapter, CIS (China) \\ Beijing Institute of Technology (China) \\ Tianjin University (China) \\ Tsinghua University (China) \\ Peking University (China) \\ Nanjing University (China) \\ Shanghai Jiao Tong University (China) \\ Zhejiang University (China) \\ Nankai University (China) \\ Capital Normal University (China) \\ Beijing University of Posts and Telecommunications (China) \\ Chongqing University (China) \\ University of Shanghai for Science and Technology (China) \\ Instrument Society of America (United States) \\ Institute of Measurement and Control (United Kingdom) \\ Hong Kong Institution of Engineers (Hong Kong, China) \\ The Society of Measurement and Control (Japan)
}


Proc. of SPIE Vol. 10617 1061701-16 Downloaded From: https://www.spiedigitallibrary.org/conference-proceedings-of-spie on 25 Apr 2023
Terms of Use: https://www.spiedigitallibrary.org/terms-of-use 